\title{
About abortion in Britain
}

\section{Introduction}

The Abortion Act 1967, which came into effect on 27 April 1968, permits termination of pregnancy by a registered practitioner subject to certain conditions. In its application to England and Wales, regulations made under the act (The Abortion Regulations 1968, statutory instrument 1968 no 390 , as amended by 1969 no 636, 1976 no 15,1980 no 1724 , and 1991 no 499 ) require any such termination to be notified within seven days, in the form prescribed in schedule 2 of the principal regulation, to the Chief Medical Officer of the Department of Health or to the Chief Medical Officer of the Welsh Office according to where the termination takes place.

Section 37 of the Human Fertilisation and Embryology Act 1990 made changes to the Abortion Act 1967. These changes came into effect on 1 April 1991 and the content of the notification of abortion form (form HSA4) was amended to reflect the changed law.

By arrangement, the Office for National Statistics (ONS) undertakes the statistical processing and analyses of the notifications.

\section{Conditions of the act and statutory grounds}

A legally induced abortion must be:

a) performed by a registered medical practitioner,

b) performed, except in an emergency, in a National Health Service (NHS) hospital or in a place for the time being approved for the purpose of the act, and

c) certified by two registered medical practitioners as justified under one or more of the following grounds:

A the continuance of the pregnancy would involve risk to the life of the pregnant woman greater than if the pregnancy were terminated;

$\mathrm{B}$ the termination is necessary to prevent grave permanent injury to the physical or mental health of the pregnant woman;

$\mathrm{C}$ the continuance of the pregnancy would involve risk, greater than if the pregnancy were terminated, of injury to the physical or mental health of the pregnant woman;

D the continuance of the pregnancy would involve risk, greater than if the pregnancy were terminated, of injury to the physical or mental health of any existing child(ren) of the family of the pregnant woman;

E there is a substantial risk that if the child were born it would suffer from such physical or mental abnormalities as to be seriously handicapped;

or in emergency, certified by the operating practitioner as immediately necessary-
F to save the life of the pregnant woman; or

$G$ to prevent grave permanent injury to the physical or mental health of the pregnant woman.

The act provides that in relation to grounds $\mathrm{C}$ and $\mathrm{D}$ the certifying practitioner may take account of the pregnant woman's actual or reasonably foreseeable environment. The changes made to the Abortion Act 1967 by section 37 of the Human Fertilisation and Embryology Act 1990 came into effect on 1 April 1991 and included a time limit of 24 weeks for abortions under statutory grounds $\mathrm{C}$ and D. Statutory grounds A, B, and E are without time limit.

\section{Category of premises/purchaser}

Except in an emergency, abortion operations may only be carried out in NHS hospitals, in certain approved services' hospitals or in other premises specifically approved by the secretary of state, such as clinics run by the British Pregnancy Advisory Service (BPAS). At the end of 1999 there were 76 such approved places and two services' hospitals.

\section{Abortion statistics}

in 1999 there were 173,701 abortions performed on women resident in england and wales.

\section{How the number and rate of abortions has changed}

From 1968 to 1973, the annual numbers of legal abortions for women living in England and Wales increased rapidly and then levelled off at about 100,000 a year. Abortion numbers then rose each year until 1991, mainly because the numbers of women in the population aged 15 to 44 (the fertile ages) grew due to a large increase in the birth rate in Britain between 1956 and 1963. There were more abortions between 1975 and 1990 because there were more women to become pregnant. A further factor in the rise in the number of abortions was the fall in the popularity of marriage among young women. Unmarried women are more likely to have an abortion if they have an unplanned pregnancy. The number of abortions has remained stable between 1998 and 1999. Reasons for this new stability could be due to abortion becoming a more acceptable solution than ever before when contraception fails or women fail to use it properly.

Numbers and rates of abortions carried out on residents of England and Wales for the last five years:

1995: 154,315 or $12.0^{\star}$

1996: 167,916 or $13.0^{\star}$

1997: 170,145 or $13.3^{\star}$

1998: 177,871 or $13.9^{\star}$ 
1999: 173,701 or $13.6^{\star}$

*per 1000 women aged $14-49$

The number of abortions in England and Wales declined between 1990 and 1995, and better use of contraception is likely to have been an important factor in this. There was a seven per cent increase in the number of abortions in 1996, largely due to the effects of a Pill scare in 1995 about the safety of certain brands of oral contraceptives. This undermined the confidence of many women in hormonal methods of contraception and decreased their use. The abortion rate has continued to rise, possibly because of continued concern about the safety of contraceptive hormones, especially among young women, and possibly because abortion is seen by more women as an acceptable way to manage an unwanted pregnancy. The increased abortion rate in 1996 was widely publicised and may have educated women that abortion is a legal and safe choice.

\section{Who pays for abortions?}

Unlike maternity services when a woman wants to continue a pregnancy, abortions are not automatically available through the NHS. On average, throughout England and Wales the NHS pays for just under three-quarters ( 74 per cent) of abortions. There are significant differences between regions. In some areas the NHS pays for more than 90 per cent of abortions, in other regions it pays for less than 50 per cent.

\section{At what gestation do most abortions occur?}

Almost 90 per cent of abortions are in the first 12 weeks of pregnancy. Just one per cent are after 20 weeks.

Abortions in England and Wales 1999 by gestation (total 173,701):

Under 9 weeks: 73,882 or $43 \%$

9-12 weeks: 80,800 or $46 \%$

13-19 weeks: 17,274 or $10 \%$

20 weeks and over: 1,745 or $1 \%$

Later abortions are often for the following reasons: The woman may not have been able to get a hospital appointment earlier in the pregnancy; she may not have realised she was pregnant (this is more common with young women and women approaching the menopause both of whom may have infrequent periods); very young women may feel unable to cope and so hide the pregnancy; sometimes the pregnancy was originally wanted but the woman's circumstances change (perhaps because she is abandoned by her partner or finds that her parents are not willing to provide her with a home or any other support); fetal abnormality is an important reason for late abortion, as many cannot be diagnosed early in pregnancy.

\section{At what age do women have abortions?}

Abortions in England and Wales 1999 by age (total 173,701):

Under $16: 3,603$ or $2 \%$

16-19: 32,807 or $19 \%$

20-24: 45,004 or $26 \%$

25-29: 38,492 or $22 \%$

30-34: 29,139 or $16 \%$

35-44: 24,096 or $14 \%$

45 and over: 502

Not stated: 58

The highest number of abortions is among women aged 20-24. However, a great deal of attention has been focused on teenagers because England and Wales has one of the highest teenage pregnancy rates for 15-19 year olds in Western Europe.

One woman in five who has an abortion is married; many others are in stable relationships. Abortion is not only an issue for single women. Forty-seven per cent of women who have abortions have at least one child already.

\section{Why do women from abroad travel to Britain for abortion?}

In 1999 almost 10,000 women who lived abroad travelled to England to have an abortion.

Most of these women came from other parts of the British Isles, mainly from Northern Ireland $(1,430)$ and the Irish Republic $(6,226)$. Those from elsewhere in the world came because abortion is available in their countries only up to 12 weeks (France and Italy) or not available at all (the Arab states), or to ensure complete confidentiality.

The numbers have fallen from their peak of 57,000 in 1973 because most other European countries now have abortion laws that are less restrictive than those in Britain. 